\title{
Two new species, including one representing a new genus, of the West African millipede family Campodesmidae (Diplopoda: Polydesmida)
}

\author{
D. VANDENSPIEGEL ${ }^{1}$, S.I. GOLOVATCH ${ }^{2} \&$ A.R. NZOKO FIEMAPONG ${ }^{3}$ \\ ${ }^{1}$ Musée Royal de l'Afrique Centrale, B-3480 Tervuren, Belgique. \\ Email: didier.van.den.spiegel@africamuseum.be (corresponding author) \\ ${ }^{2}$ Institute for Problems of Ecology and Evolution, Russian Academy of Sciences, \\ Leninsky prospekt 33, Moscow 119071, Russia. \\ Email: sgolovatch@yandex.ru (corresponding author) \\ ${ }^{3}$ Laboratoire de Zoologie, Université Yaoundé 1, BP812, Cameroon. \\ Email: armandnzoko@gmail.com \\ ${ }^{1}$ urn:1sid:zoobank.org:author:CE8C3D01-28AD-43F7-9D4F-04802E68CB1A \\ ${ }^{2}$ urn:Isid:zoobank.org:author:71532F45-BDD5-415D-BC54-86256E5D5D4A \\ ${ }^{3}$ urn:1sid:zoobank.org:author:ECDC7821-D8DA-49D4-9D6A-13A6E732863E
}

\begin{abstract}
A new genus, Campodesmoides gen. nov., is described to only encompass $C$. corniger sp. nov., from Cameroon. This genus and species is distinguished from the few known species of the small western African family Campodesmidae, all currently in Campodesmus, by the much longer antennae and legs, the normal pore formula with ozopores borne on porosteles, and the suberect and distally twisted gonopod, coupled with peculiar horns on a few anterior postcollum segments. A new Campodesmus is also described, C. alobatus sp. nov., from Ivory Coast, which differs from congeners primarily in the lack of a dorsal/lateral lobe on the otherwise usual and strongly subcircular gonopod telopodite, albeit the latter is not directed mesad, but held subparallel to the main body axis.
\end{abstract}

Key words. Myriapoda, taxonomy, Ivory Coast, Cameroon.

VandenSpiegel D., Golovatch S.I. \& Nzoko Fiemapong A.R. 2015. Two new species, including one representing a new genus, of the West African millipede family Campodesmidae (Diplopoda: Polydesmida). European Journal of Taxonomy 139: 1-11. http://dx.doi.org/10.5852/ejt.2015.139

\section{Introduction}

The small millipede family Campodesmidae is currently known to comprise "about eight species" from Liberia, Sierra Leone, Ghana, Ivory Coast and Nigeria (Hoffman 1980, 1982), albeit Demange (1971) had considered and keyed only seven. All of them are assigned to the genus Campodesmus Cook, 1896, which is characterized by a dark medium-sized body (17-38 mm long) with more or less strongly tuberculate metaterga and only moderately declivous paranota (Schiøtz 1966). The modestly or even not enlarged paranota 2 suggest incomplete or imperfect volvation, i.e., enrollment into only a partial coil (Golovatch 2003). Ozopores are only present on paranota 5 and 7. The gonopod aperture is rather large, transversely oval, the edges at least partly being elevated and the gonopods almost fully exposed. 
The gonocoxae are elongated subcylindrical, fused basally, at best poorly setose, concealed inside the aperture. The telopodites are long, strongly subcircular, directed anteromesally, crossing in situ, on the dorsal/lateral face usually with a prominent, variously shaped lobe (= prefemoral process) at the base of the telopodite.

Interestingly, the course of the seminal groove has never been traced and properly described in the literature (Hoffman 1951, 1982; Schiøtz 1966; Demange 1971). Based on the available illustrations, however, the family and genus could additionally be characterized by the lack of a special solenomere to support at least the terminal part of the seminal groove.

The present paper records two new species of Campodesmidae: 1) a new Campodesmus from Ivory Coast, and 2) a second genus of the family, Campodesmoides gen. nov., a monotypic taxon from Cameroon. These two genera are markedly distinct from each other both in gonopod conformation and several somatic characters.

\section{Material and methods}

All material treated here derives from the collection of the Musée Royal de l'Afrique Centrale (MRAC), Tervuren, Belgium, with only one paratype shared with the holdings of the Zoological Museum of the Moscow State University (ZMUM), Moscow, Russia. The samples are stored in 70\% ethanol. Specimens for scanning electron microscopy (SEM) were air-dried, mounted on aluminium stubs, coated with gold and studied using a JEOL JSM-6480LV scanning electron microscope. Photographs were taken with a Leica DFC 500 digital camera mounted on a Leica MZ16A stereo microscope. Images were processed with the Leica Application Suite software.

\section{Results}

Class Diplopoda Blainville-Gervais, 1844

Order Polydesmida Leach, 1814

Family Campodesmidae Cook, 1895

Genus Campodesmoides gen. nov. urn:lsid:zoobank.org:act:D7DFD21A-C64C-40E4-9CA2-637CAB4E16A2

\section{Diagnosis}

Same as for Campodesmoides corniger sp. nov., due to monotypy of this genus.

\section{Etymology}

The name of this genus emphasizes the attribution of the new genus to the Campodesmidae which has been known so far by the single genus Campodesmus. Gender masculine.

\section{Type species}

Campodesmoides corniger sp. nov.

Campodesmoides corniger sp. nov. urn:1sid:zoobank.org:act:E20A8CC8-F56C-4499-B1F0-F3D541275368 Figs 1-3

\section{Diagnosis}

A species of Campodesmidae which differs from other species of the genus Campodesmus, the only hitherto recognized genus of Campodesmidae, by the long and only slightly clavate antennae, which 
reach behind segment 3 when stretched dorsally; the considerably longer legs which in the male are about 1.5 times as long as midbody height; the normal pore formula: 5, 7, 9, 10, 12, 13, 15-19, the ozopores being borne on conspicuous porosteles (versus reduced to 5, 7 without porosteles); the more dorsally situated paranota which are set at the upper $1 / 4$ of midbody height (versus about half of midbody height); the nearly flat sterna and the gonopod telopodites being suberect, in situ directed forward, not crossing mesally, each with a clearly twisted solenophore devoid of a distinct solenomere.

\section{Etymology}

To emphasize the high, vertical, paramedian horns present on metatergum 2, these growing increasingly small on metatergum 3 and, especially, 4; noun in apposition.

\section{Material examined}

\section{Holotype}

CAMEROON: ${ }^{\Uparrow}$, Ongot, $\mathrm{N} 03^{\circ} 52^{\prime}$, E $011^{\circ} 21^{\prime}$, c. 830 m a.s.l., open terrain, 26 Apr. 2014, leg. A. Nzoko, MRAC 22679.

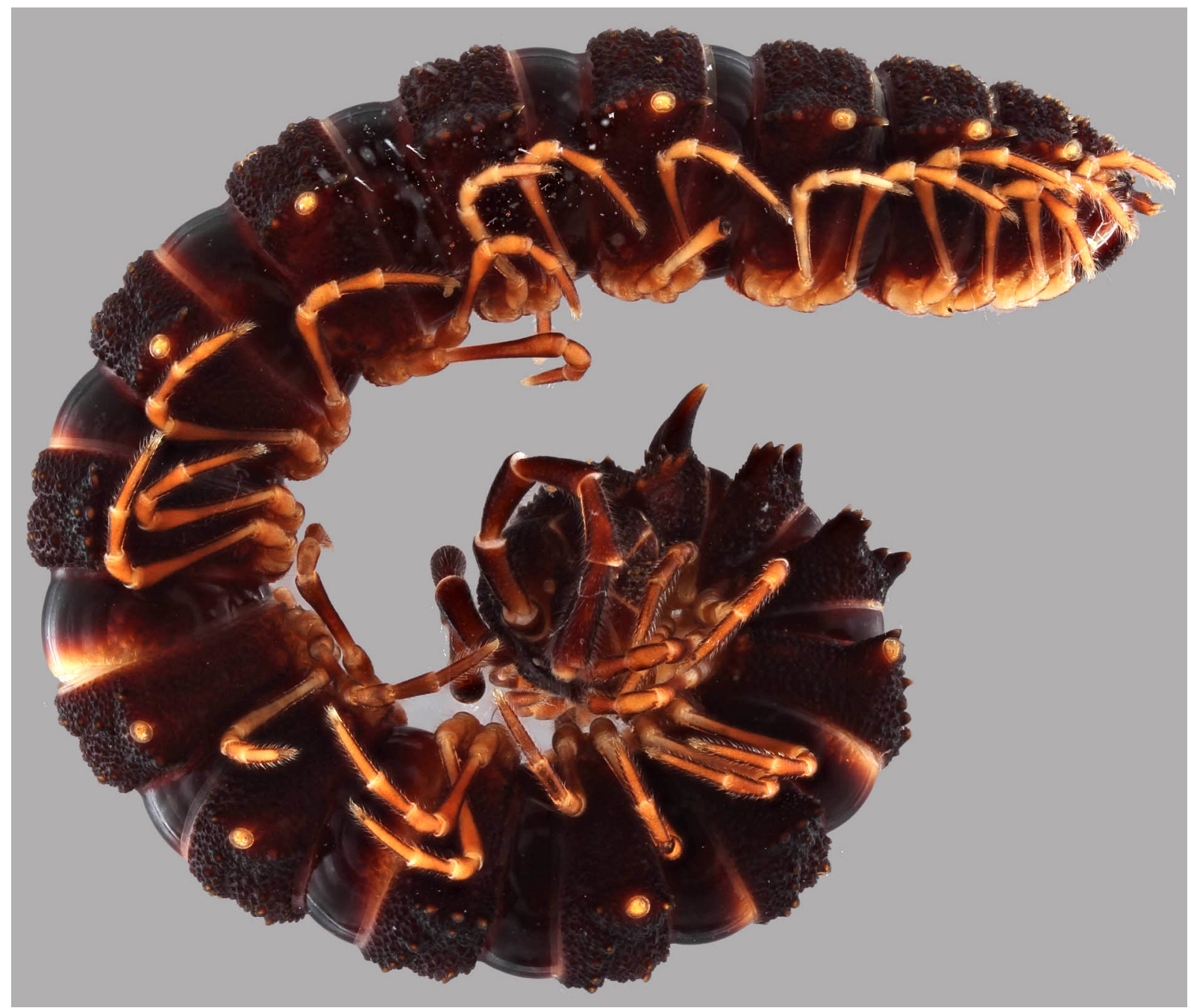

Fig. 1. Habitus of Campodesmoides corniger sp. nov., $\widehat{\jmath}$, holotype, lateral view. Photo by J. Brecko, not to scale. 


\section{Paratypes}

CAMEROON: 1 , same locality, together with holotype, MRAC 22.681; 1 , same locality, 29 Nov.

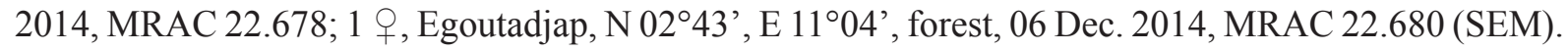
All leg. A. Nzoko.

\section{Description}

Length of holotype $c .26 \mathrm{~mm}$, width on midbody pro- and metazonae 2.5 and $5.0 \mathrm{~mm}$, respectively. female paratypes $25-30 \mathrm{~mm}$ long, $2.5-3.6$ and $3.6-5.0 \mathrm{~mm}$ wide on pro- and metazonae, respectively. Coloration from light grey-brown (female) to blackish brown (male, female) (Fig. 1), darker specimens
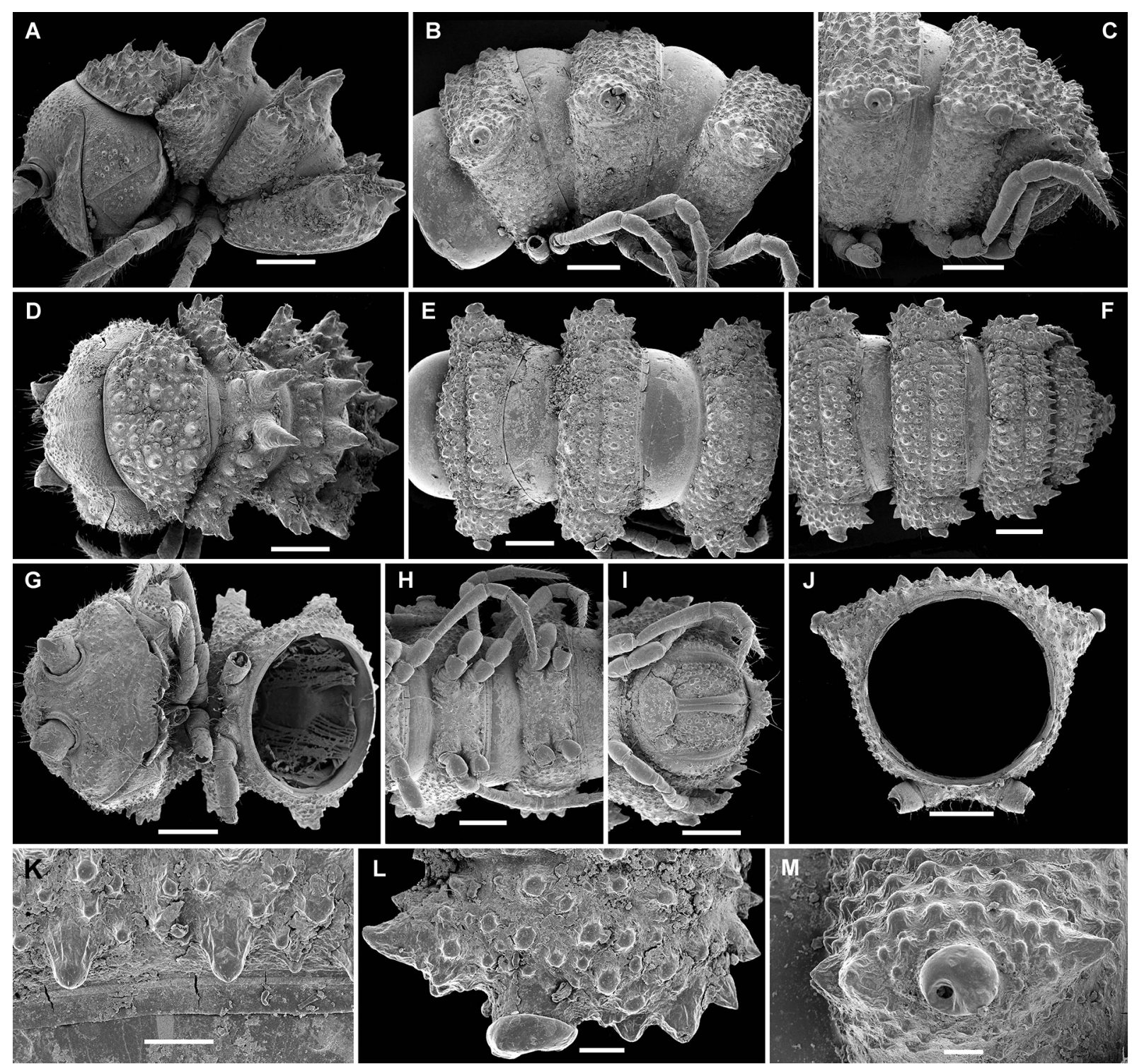

Fig. 2. SEM micrographs of Campodesmoides corniger sp. nov., + , paratype, MRAC 22.680. A, D, G. Anterior part of body, lateral, dorsal and ventral views, respectively. B, E, H. Midbody segments, lateral, dorsal and ventral views, respectively. C, F, I. Posterior part of body, lateral, dorsal and ventral views, respectively. J. Cross-section of a midbody segment, caudal view. K. Limbus and adjacent structures. L-M. Poriferous paratergite with porostele, dorsal and lateral views, respectively. Scale bars: $\mathrm{A}-\mathrm{J}=0.5 \mathrm{~mm} ; \mathrm{K}-\mathrm{M}=0.1 \mathrm{~mm}$. 
with brown to chocolate brown antennae and legs; tips of antennae, distal parts of paranota 5, 7,9 and 13 together with their porosteles, as well as the remaining porosteles (male, female) or only all porosteles (female) yellowish to nearly pallid.

HEAD. Except for a bare and rather densely setose clypeolabral region, very densely microdenticulatemicrotuberculate-microgranulate, interantennal isthmus almost as broad as diameter of antennal socket (Fig. 2). Antennae long and only slightly clavate due to a somewhat higher antennomere 6, in situ reaching behind segment 3 when stretched dorsally; only antennomere 6 with a dorso-apical group of tiny bacilliform sensilla; in length, antennomere $6>2>3=5>1>7$; apical segment with the usual four sensory cones.

Body. With 20 segments (male, female). In width, segment $3=4<$ head $=$ collum $=5-17<2$ (male), or collum $<$ head $=3=4<2<5-17$ (female); body rapidly tapering from segment 18 towards telson. Collum transversely ellipsoid, far from covering entire head from above, dorsal surface rather regularly and densely tuberculate, with two transverse rows of higher $2+2$ and $4+4$ tubercles in caudal half, paranota bearing 2-3 lateral teeth (Figs 1, 2A, D). Prozonae smooth and weakly shining; metazonae dull, densely microtuberculate or microgranulate all over, cerotegument well-developed, sometimes in places clothed with a crust of soil; dorsal surface usually with three regular, transverse rows of normally small tubercles or short spines; stricture very delicately striolate. Metatergum 2 with two transverse rows of spines, $2+2$ per row, mid-dorsal pair in rear row being only slightly separated, unusually high, vertical and horn-shaped compared to very small remaining spines; paranota 2 strongly elevated, directed dorsolaterad at about $45^{\circ}$, each with 3-4 apical teeth (Figs 1, 2A, D). Tuberculation pattern persisting on metaterga 3 and 4 as well, but mid-dorsal pair of horns first considerably and then much shorter, respectively, each horn thereby carrying a subapical denticle on caudal face (Fig. 2A, D); paranota 3-8(9) increasingly less strongly elevated to become subhorizontal (Figs 1, 2B-C, E-F, J). Metaterga 5-19 with a faint, but visible, transverse, midtergal impression separating first transverse row of $1+1$ (segment 5), $2+2$ (segments 6-14) or 3+3 (segments 15-19) small tubercles from two further transverse rows, middle row usually consisting of slightly higher tubercles: $3+3$ (segments $5-14)$ or 4(5) + 4(5) (segments 15-19); caudal row located near caudal margin, usually consisting of
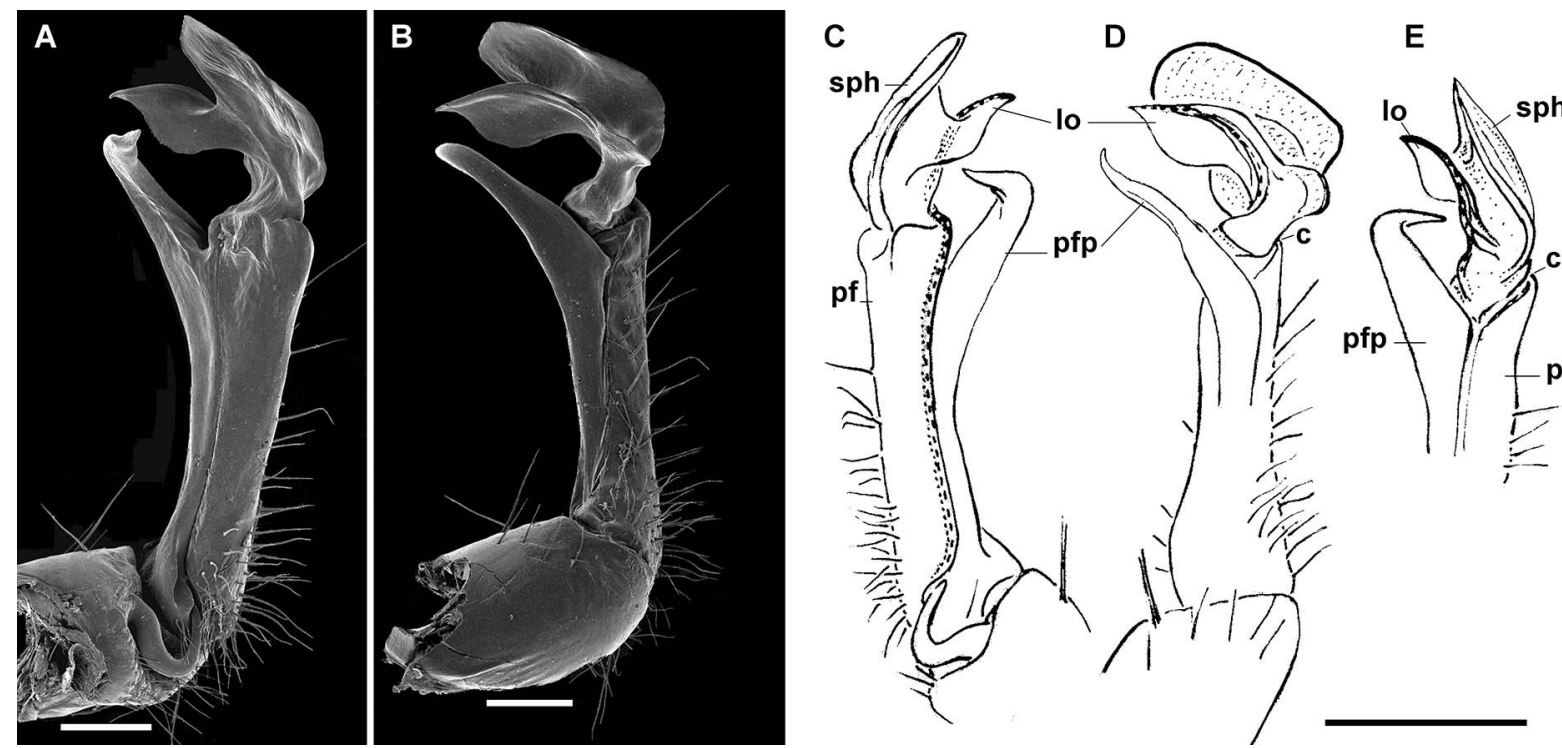

Fig. 3. Campodesmoides corniger sp. nov., $\hat{\jmath}$, holotype. A-B. Left gonopod, mesal and lateral views, respectively. C-E. Right gonopod, mesal, lateral and ventral views, respectively. Scale bars $=0.2 \mathrm{~mm}$. Abbreviations are explained in the text. 
particularly small tubercles, yet clear enough against a microgranulate/microtuberculate background: $2+2$ (segments 5-14) or 3(4) +3(4) (segments 15-19). Poreless paranota usually with 4-5 distinct teeth at lateral margin, pore-bearing ones normally subtruncate, with 1-2 teeth at both fore and rear corners, and a prominent, midlength porostele (Figs 1, 2B-C, E-F, J). Pore formula normal, ozopores always borne on somewhat mushroom-shaped porosteles. Paranota set high (mostly at about upper $1 / 4$ of body height, dorsum thus being only moderately convex), inclined caudad and increasingly clearly protruding behind rear tergal margin from segment 17 towards telson (Figs 1, 2C, F), considerably broader, and porosteles longer in male than in female. A thin dark axial line sometimes traceable through a transparent tegument. Pleurosternal carinae absent, a few small tuberculations in their place (Fig. 2A). Limbus entire (Fig. 2K). Epiproct short, small, subtruncate, coniform, with a pair of prominent subapical papillae (Fig. 2C, F, I). Hypoproct nearly semi-circular with $1+1$ caudal setae very distinctly separated and borne on minute knobs (Fig. 2I).

Sterna. Broad, about twice as broad as coxa length, almost flat, axial impression absent (Fig. 2H). Gonapophyses on male coxae 2 vestigial (Fig. 2G). Legs long to very long, about $0.9-1.0$ or 1.51.6 times as long as midbody height (female and male, respectively), very slender; in length, femur $>$ tarsus $>$ prefemur $=$ postfemur $=$ tibia $=$ coxa; claw very small, very slightly curved; ventral surface of tarsi densely setose, but forming no brushes.

GonOPOD. Aperture transversely ovoid, large, its lateral and posterior edges slightly elevated, fully concealing gonocoxae and bases of telopodites. Gonopod coxites medium-sized, subcylindrical, fused at base to a small membranous sternal remnant, poorly setose distodorsally, including a pair of very closely placed, distalmost, particularly long setae. Cannulae slender, without peculiarities (Fig. 3A-B). Telopodites in situ directed forward, held subparallel to each other, suberect, not crossing each other mesally. Prefemoral (= densely setose) portion (pf) subcylindrical, very long and slender, untwisted, almost not enlarged towards an oblique apical cingulum (c) delimiting it from femorite, with a long, slightly curved, distodorsal process (pfp). Femorite clearly twisted, lamellar, about half as long as pf, forming a large, rounded, apical lobe $=$ solenophore $(\mathrm{sph})$ to protect a smaller, parabasal lobe (lo) carrying terminal part of seminal groove on its distal rib. Seminal groove first running fully on mesal side of pf, then moving laterad above $\mathrm{c}$ onto distal rib of lo to end at tip of lo (Fig. 3C-E).

\section{Remark}

This new genus and species extends the range of Campodesmidae to Cameroon in the east, the family also being recorded in that country for the first time.

Genus Campodesmus Cook, 1896

Campodesmus alobatus sp. nov. urn:1sid:zoobank.org:act:5483AFA3-1222-4B5F-B7C7-B85EEE2FFB58

Figs $4-6$

\section{Diagnosis}

Differs from other members of the genus in the complete lack of a parabasal process/lobe on the gonopod telopodite which is not directed mesally, but held subparallel to the main body axis, coupled with much more numerous, nearly undifferentiated and low tubercles on metaterga and the presence of deeply incised and clearly separated antero- and caudolateral lobulations on the postcollum paranota.

\section{Etymology}

The name of this species emphasizes the absence of a dorsal/lateral parabasal process/lobe from the gonopod telopodite. 


\section{Material examined}

\section{Holotype}

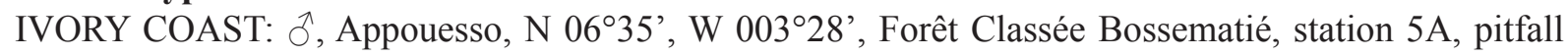
trapping, 30 Nov. 1994, leg. R. Jocqué \& N. Séabé, MRAC 17.264.

\section{Paratypes}

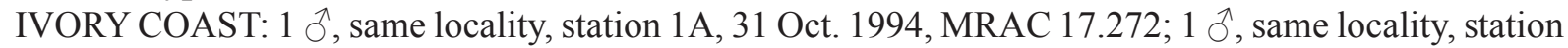

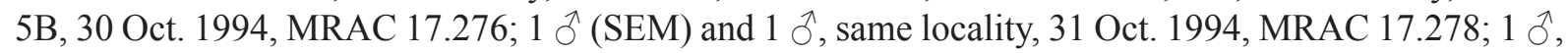
same locality, station 5D, 31 Oct. 1994, ZMUM $\rho 2665$. All leg. R. Jocqué \& N. Séabé.

\section{Description}

Length of holotype $c .17 \mathrm{~mm}$, width on midbody pro- and metazonae 1.7 and $3.6 \mathrm{~mm}$, respectively. Paratypes (males) also $c .17 \mathrm{~mm}$ long, width on midbody pro- and metazonae $1.6-1.7$ and $3.0 \mathrm{~mm}$, respectively. Coloration from light grey-brown to brown (Fig. 4); clypeolabral region, antennae, prozonae, venter, legs and tip of epiproct pallid to light yellow; stricture as brown as metazonae.

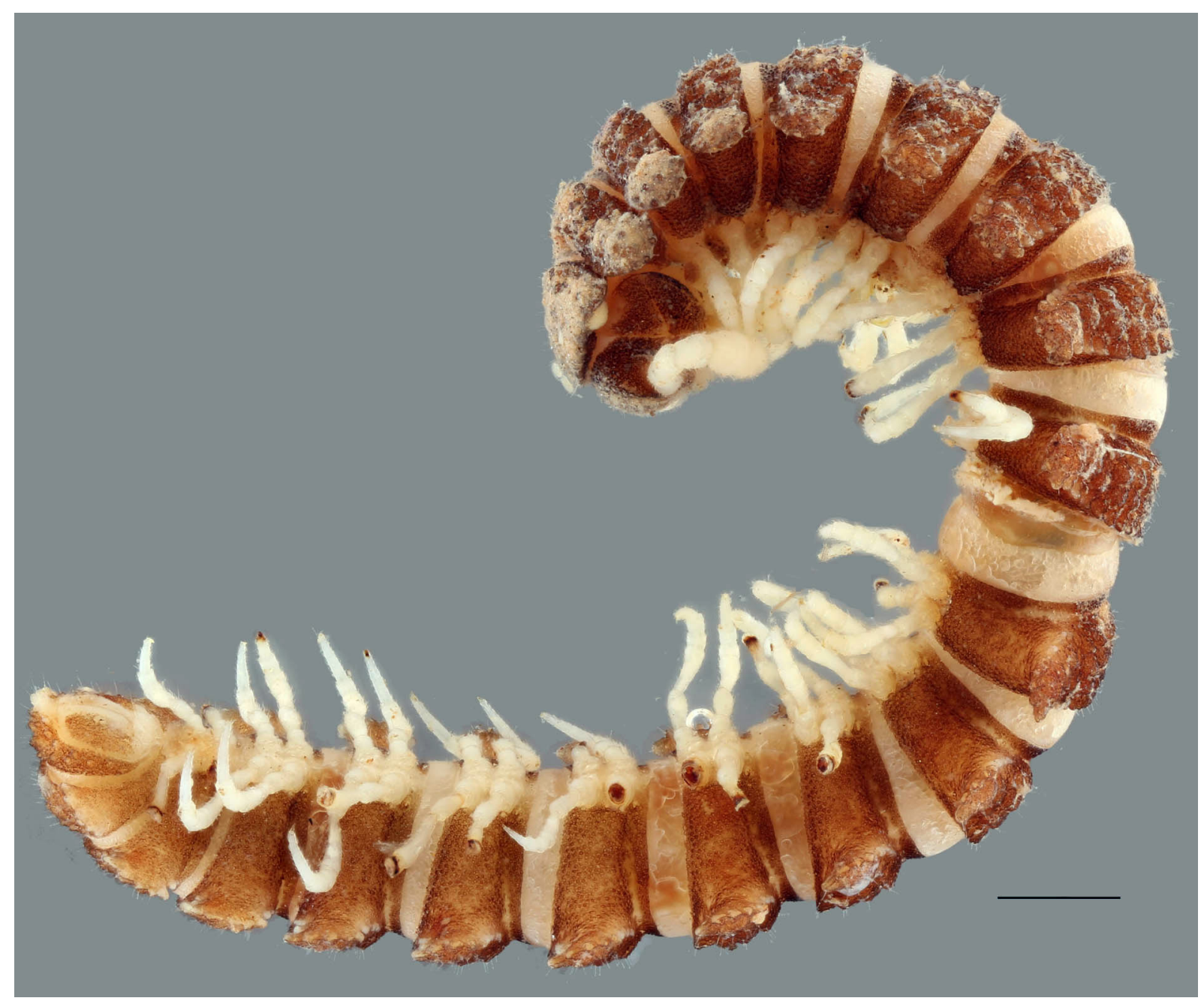

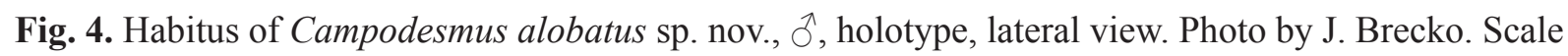
bar $=1.0 \mathrm{~mm}$. 

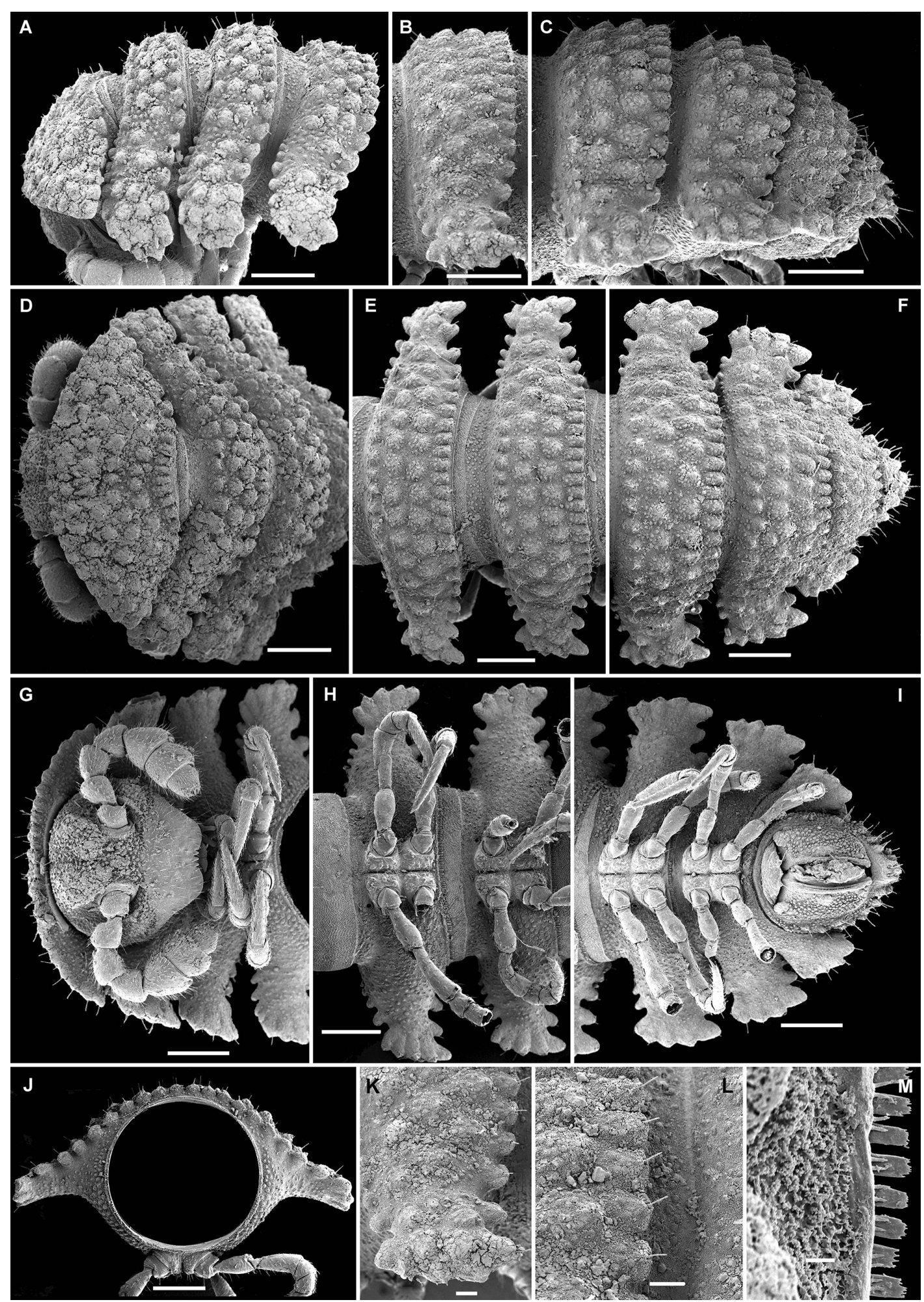

Fig. 5. SEM micrographs of Campodesmus alobatus sp. nov., paratype, O, MRAC 17.278. A, D, G. Anterior part of body, lateral, dorsal and ventral views, respectively. B, E, H. Midbody segments, lateral, dorsal and ventral views, respectively. C, F, I. Posterior part of body, lateral, dorsal and ventral views, respectively. J. Cross-section of a midbody segment, caudal view. K. Midbody paratergum, lateral view. L. Fine structure of pro- and metazonae, as well as of stricture between them, subdorsal view. $\mathbf{M}$. Limbus and adjacent structures. Scale bars: A-J $=0.5 \mathrm{~mm} ; \mathrm{K}-\mathrm{L}=0.1 \mathrm{~mm} ; \mathrm{M}=0.01 \mathrm{~mm}$. 
HEAD. Densely setose, clypeolabral region smooth, remaining parts densely microdenticulatemicrogranulate, interantennal isthmus $c .1 .5$ times as broad as diameter of antennal socket. Antennae short and strongly clavate, C-shaped, antennomere 5 largest and longest, but only a little larger than $6^{\text {th }}$, both with a dorso-apical group of tiny bacilliform sensilla; apical segment with usual four sensory cones (Figs 4, 5G).

BoDy. With 20 segments (male). In width, head $<<$ collum $=$ segment $2<3<4<5-17$; thereafter body rapidly tapering towards telson. Collum transversely ellipsoid, subflabellate, covering most of head from above, dorsal surface rather regularly and densely tuberculate, with about 4-5 transverse rows of round, setigerous, undifferentiated tubercles lying between a moderately crenulate/lobulate and regularly rounded anterior margin and a clearly ribbed and almost straight caudal edge; small, but discernible caudal paranota with a rather sharp lateral tooth (Figs 4, 5A, D, G). Prozonae smooth and poorly shining, stricture finely microgranulate; metazonae dull, densely tuberculate and microgranulate over entire surface; cerotegument well-developed, sometimes in places clothed with a crust of soil; dorsal surface usually with two regular, mixostictic (= not regularly longitudinal) transverse rows of normally similar round tubercles, much like on collum, lying between a fore row of denser and smaller knobs/tubercles behind stricture and a densely ribbed caudal edge represented by a flatter row of oblong tubercules (Fig. 5A-F). Paranota 2 not enlarged compared to following ones (Figs 4, 5A). Postcollum paranota set rather low (at about half of midbody height, thus dorsum being very strongly convex), strongly declivous, continuing the outline of dorsum, but their tips not reaching level of venter (Fig. 5A-C, J); lateral margin of paranota usually 5-lobulate, laterals continuing into even more deeply lobulate caudo- and anterolaterals both at caudal and fore margin, respectively; caudo- and anterolateral lobulations continuing both caudal and fore rows of tubercles at base of paranota, respectively (Figs 4, 5A-I). Caudal corner of paranota increasingly strongly inclined caudad behind rear tergal margin only in segments 17-19 (Fig. 5C, F, I). Tergal setae very short and thin (Fig. 5A-L). Ozopores inconspicuous, opening flush on tergal surface at about midlength of paranota 5 and 7 off lateral margin. Pleurosternal carinae absent (Fig. 5G). Limbus microcrenulate, with microserrate tips of crenulations, these latter clearly separated from one another (Fig. 5M). Epiproct short, small, subtruncate, slightly flattened dorsoventrally, tuberculate dorsally, with a pair of rather large subapical papillae (Figs 4, 5C, F, I). Hypoproct nearly semi-circular with $1+1$ caudal setae very distinctly separated and borne on minute knobs (Fig. 5I).
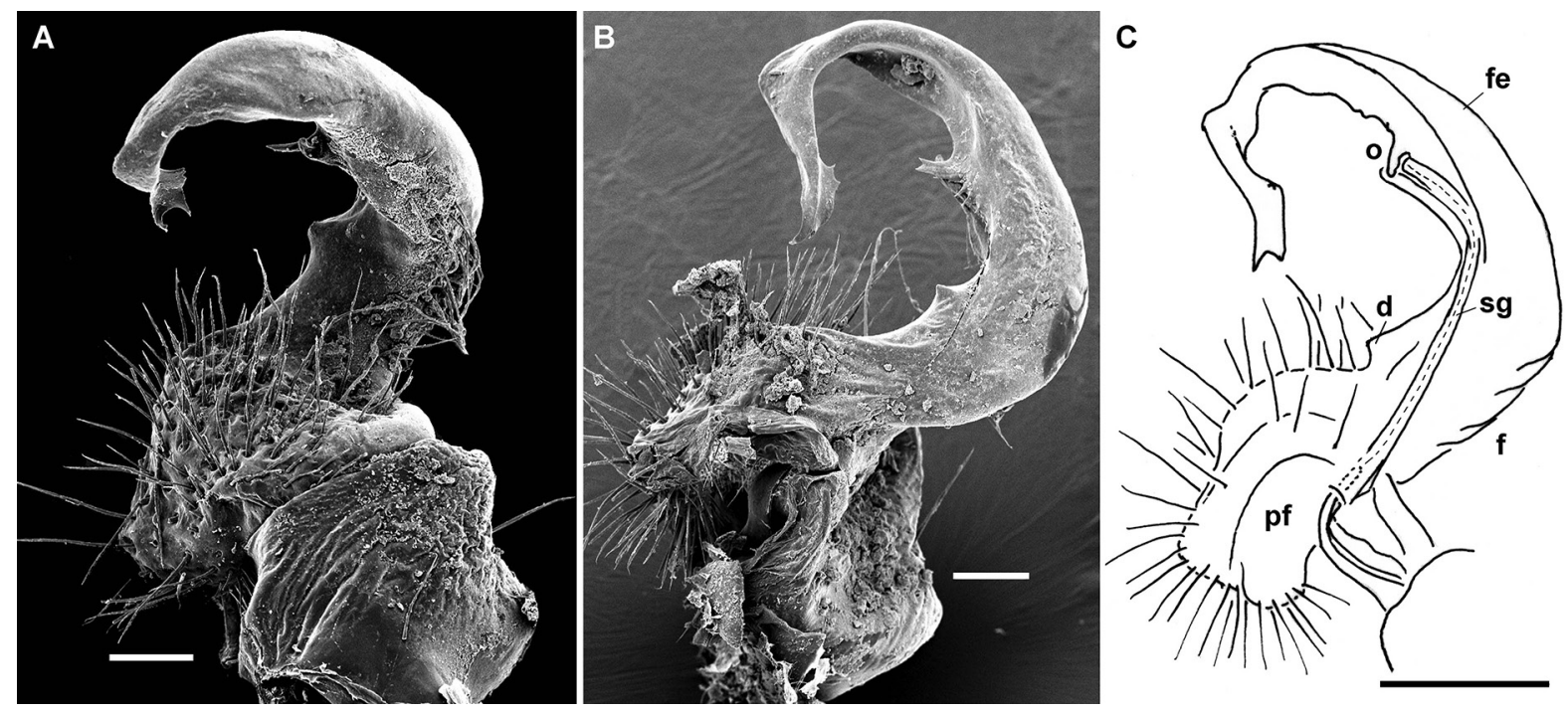

Fig. 6. Campodesmus alobatus sp. nov., paratype, $\widehat{\jmath}$, MRAC 17.278. A-B. Left gonopod, ventrolateral and submesal views. C. Right gonopod, mesal view. Scale bars: A-B $=0.1 \mathrm{~mm} ; \mathrm{C}=0.2 \mathrm{~mm}$. Abbreviations are explained in the text. 
STERnA. Broad, almost twice as broad as coxa length, with a very deep axial impression (Fig. 5G-I). Gonapophysis on male coxae 2 a small tubercle. Legs short, even in male about 0.9-1.0 times as long as midbody height, very slender; in length, femur $>$ tarsus $>$ prefemur $>$ postfemur $=$ tibia $=$ coxa; claw very small, very slightly curved; ventral surface of tarsi densely setose, but forming no brushes.

GoNOPOD. Aperture transversely ovoid, large, its lateral and posterior edges slightly elevated, fully concealing gonocoxae and bases of telopodites. Gonopod coxites medium-sized, subcylindrical, fused at base to a small membranous sternal remnant, each with only one long distodorsal seta (Fig. 6A, B). Cannulae long and slender, without peculiarities. Telopodites rather regularly curved caudad, in situ held subparallel to each other, subcircular, long, slender and quite simple (Fig. 6). Prefemoral (= densely setose) portion (pf) subcylindrical, rather long, totally devoid of outgrowths. Femorite (fe) with a small parabasal denticle (d) on ventral face and a series of inconspicuous folds (f) on opposite side. Seminal groove (sg) running entirely on mesal side, terminating at about halfway along fe, at base of a small denticle (o), with neither a hairpad nor an accessory seminal chamber. Tip of fe slightly broadened and bifid (Fig. 6C).

\section{Remarks}

The species described above is the $8^{\text {th }}$ known species of Campodesmus which, despite the peculiarities referred to in the diagnosis, remains a rather typical congener. This is primarily evidenced by the gonopod conformation which shows long and subcircular telopodites. Such non-gonopod characters as low paranota, a reduced pore formula, short antennae and legs etc. also attest to the unequivocal assignment of this new species to Campodesmus (cf. Hoffman 1951; Schiøtz 1966; Demange 1971).

The clearly abbreviated seminal groove in C. alobatus sp. nov., which only extends to about the midlength of an untwisted gonopod femorite, invites comparisons with other congeners. Regrettably, no such information is available in the literature. Schiøtz (1966) attempted to group most of the species of Campodesmus, but more data are needed, including the course of the seminal groove, to reach more secure conclusions.

\section{Acknowledgements}

The last two authors are greatly obliged to the Musée Royal de l'Afrique Centrale, Tervuren, Belgium for the invitation to join this project. Special thanks go to Jonathan Brecko (MRAC) for taking the colour pictures and to Christophe Allard for technical assistance.

\section{References}

Demange J.M. 1971. Myriapodes Diplopodes. Le massif des Monts Loma (Sierra Leone). Fascicule I. Mémoires de l'Institut Fondamental d'Afrique Noire 86: 191-240.

Golovatch S.I. 2003. A review of the volvatory Polydesmida, with special reference to the patterns of volvation (Diplopoda). African Invertebrates 44 (1): 39-60.

Hoffman R.L. 1951. The diplopod family Campodesmidae (Polydesmida). Journal of the Washington Academy of Sciences 41 (6): 209-212.

Hoffman R.L. 1980. Classification of the Diplopoda. Muséum d'histoire naturelle, Genève.

Hoffman R.L. 1982. Diplopoda. In: Parker S.P. (ed.) Synopsis and Classification of Living Organisms. Vol. 2: 689-724. McGraw-Hill, New York.

Schiøtz V. 1966. Notes on West African diplopods I. The family Campodesmidae (Polydesmida). Vidensksbelige Meddelelser fra Dansk naturhistorisk Forening 129: 81-104. 
Manuscript received: 4 June 2015

Manuscript accepted: 11 August 2015

Published on: 28 September 2015

Topic editor: Rudy Jocqué

Desk editor: Charlotte Thionois

Printed versions of all papers are also deposited in the libraries of the institutes that are members of the EJT consortium: Muséum national d'Histoire naturelle, Paris, France; Botanic Garden Meise, Belgium; Royal Museum for Central Africa, Tervuren, Belgium; Natural History Museum, London, United Kingdom; Royal Belgian Institute of Natural Sciences, Brussels, Belgium; Natural History Museum of Denmark, Copenhagen, Denmark. 